\title{
Trayectoria laboral de los sociólogos en tiempos de cambio y de conflicto
}

\section{RESUMEN}

La sociología como profesión tiene sus inicios a partir de su profesionalización en la década de 1960, en que se sientan las bases teóricas, metodológicas e instrumentales, con lo que se garantiza su pertinencia y continuidad como ciencia social. En este artículo, que es parte de un libro próximo a publicarse, se presenta acerca de la trayectoria laboral de los sociólogos en tiempos de cambio y de conflicto, donde se plantea la siguiente pregunta de investigación: ¿Cómo ha sido la trayectoria laboral de los sociólogos en tiempos de cambio y de conflicto? El objetivo es conocer la trayectoria laboral desde los ańos de 1960 hasta la actualidad, además de destacar los antecedentes familiares para comprender la movilidad intergeneracional a través de su nivel educativo y laboral.

PALABRAS CLAVE: sociología, mercado laboral, movilidad intergeneracional.

\section{Labor trajectory of sociologists in times of change and conflict}

\begin{abstract}
Sociology as a profession has its beginnings from its professionalization in the 1960s, in which the theoretical, methodological and instrumental foundations are laid down, which guarantees its relevance and continuity as a social science. In this article, which is part of a forthcoming book, it is presented about the work history of sociologists in times of change and conflict, where the following research question is posed: How has the work experience of the Sociologists in times of change and conflict? The objective is to know the work trajectory from the 1960s to the present, in addition to highlighting the family background to understand intergenerational mobility through their educational and work level.
\end{abstract}

KEYWORDS: sociology, labor market, intergenerational mobility. 


\section{Introducción}

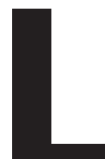

a investigación es de corte cualitativo y enfoque interpretativo y para cumplir con el objetivo se retomó entrevistas realizadas a los alumnos del último ciclo de estudios (2014), así como egresados de la Escuela de sociología de la Universidad Nacional Mayor de San Marcos, a quienes se les solicitó por e-mail, hacer un breve resumen de su trayectoria laboral y con algunos de ellos conversación personal en el cafetín de la Facultad. Era importante esta información por cuanto son personas que vienen ejerciendo su profesión en diferentes campos del mundo laboral. Se solicitó a un total de 50 egresados, de los cuales contestaron 35 y se ha seleccionado los más representativos, principalmente de las últimas promociones, con la finalidad de ver su trayectoria laboral en una sociedad donde hoy en día la estabilidad laborar para los sociólogos no es igual que para las otras profesiones.

En el artículo, hacemos una breve pincelada acerca de la trayectoria laboral de los sociólogos, desde su institucionalización hasta la actualidad. En ese sentido es importante destacar que los que nos formamos como profesionales en la década de 1960, podemos afirmar que durante los dos primeros ańos de cultura general, recibimos una muy buena formación humanística, principalmente a través de los cursos de filosofía, literatura, historia, psicología, que estructuró nuestra personalidad. En el ciclo doctoral el plan de estudios tenía una orientación profesionalizante, donde el conocimiento de la sociedad se hacía a través de la la medición de las propiedades de los hechos sociales, mediante las llamadas variables, de tal modo que era necesario la utilización de las técnicas estadísticas y otros instrumentos.

En la década del 70, con la creación de diversas instituciones corporativas creadas por la Junta Militar de Gobierno, la demanda de profesionales de las ciencias sociales, principalmente la sociología fue en ascenso, algunos han calificado a este periodo como el boom de la sociología. Esta situación cambia en la década del 80, debido a diversos problemas que se dan en la sociedad: acentuación de la crisis económica, el levantamiento de Sendero Luminoso y el MRTA, las continuas huelgas de docentes y administrativos en la universidad y el papel de los medios de comunicación estigmatizando a los sanmarquinos como pertenecientes a estos grupos violentistas. Los sociólogos tuvieron muchas dificultades para incorporarse al mercado laboral, tanto pública como privada.

En la actualidad, los egresados de la Escuela de Sociología trabajan en diferentes instituciones tanto públicas como privadas. A partir de los propios testimonios de experiencia laboral se destaca la experiencia ocupacional de cada uno de ellos; quienes manifiestan que la formación general que recibieron en la universidad no fue suficiente para responder a las nuevas exigencias del mercado laboral, motivo por el cual tuvieron que llevar un conjunto de cursos de posgrado y de especialización, con la finalidad de posicionarse en las instituciones donde trabajan. Hoy en día las empresas ven en los profesionales Sociólogos que pueden realizar diversas actividades específicas, pero que a su vez exigen nuevos conocimientos como: el modelo del Triple Bottom Line, el Global Reporting Initiative (GRI), además de programas de análisis cuantitativo como el SPSS y programas de análisis cualitativo como el ATLAS TI, Word, Excel, PPT, entre otros muchos programas que existen.

En este sentido, la Escuela de Sociología, tiene que replantear su malla curricular en cuanto al manejo instrumental que hoy en día exige las empresas, sin descuidar su formación en cuanto a la investigación que permite crear nuevos conocimientos y un buen sustento teórico acorde al desarrollo de las teorías sociológicas en la actualidad. Se concluye haciendo algunas referencias acerca de las condiciones educativas y laborales de los padres de familia de los egresados, puntualizando que en esta sucesión intergeneracional, de padres a hijos, no existe relación académica en el campo de las ciencias sociales.

\section{Nacimiento de una nueva profesión}

La sociología fue ganando independencia conforme avanzó en la delimitación de su objeto de estudio y consiguió su propia matriz disciplinar en lo teórico, metodológico e instrumental. A esta tarea es a la que se encomendaron principalmente los sociólogos Aníbal Ísmodes Cairo y José Mejía Valera con la finalidad de enriquecer el debate a la luz de los procesos sociales y políticos que vivía el país. Agregándose a todo esto que, desde fines de la década del cincuenta los movimientos sociales y políticos fueron en ascenso constituyéndose en un importante campo de estudio que concitó la atención de diversos intelectuales académicosy políticos. 
Este inusitado ascenso de conflictividad se debió, en gran medida, a que fue por aquellos ańos cuando gran parte de las herramientas analíticas existentes se mostraron incapaces para dar respuestas rigurosas a los procesos históricos de movilización emergentes: El movimiento campesino de Pasco Algolán que busca recuperar sus tierras usurpadas por la hacienda Algolán de los Aspíllaga, el movimiento campesino de Lares y la Convención con Hugo Blanco y el levantamiento de jóvenes en la guerrilla con Luis de la Puente, los golpes militares del 1948, 1962, 1968, el surgimiento de las barriadas en Lima. Trataron de dar respuesta desde las experiencias estudiantiles, feministas, pacifistas, entre otras; pero, había necesidad de analizar y reflexionar desde nuevas ópticas sobre formas de acción colectiva y conflictos sociales que aparecían como novedosos si se comparaban con las maneras clásicas de contención política. Es así como surge la institucionalización de la sociología como carrera profesional con la finalidad de explicar estos problemas desde nuevos enfoques teóricos y metodológicos.

Karl Popper en su libro "sociedad abierta, universo abierto" señaló que de alguna manera todas las personas son filósofos, porque todos siempre se han preguntado: ¿quiénes son, de dónde vienen y a dónde van? De la misma manera podemos afirmar que todas las personas son sociólogos, porque todos tienen algún tipo de idea y de convicción, de cómo es la sociedad para poder actuar en ella, además de que hoy en día utilizan en su lenguaje muchos términos de la sociología con bastante naturalidad, sin preguntarse acerca de su naturaleza y definición. Esta forma de ver la sociedad de manera espontánea, de hecho es una forma de hacer sociología, que algunos denominan "sociología espontánea”. Pero, esta mirada espontánea no es suficiente para tener una identidad como de alguien que pertenece al mundo de las ciencias sociales o el de la sociología. Esta construcción subjetiva a través del sentido común, resulta útil para comprender y explicar la sociedad desde la rigurosidad de la sociología como ciencia. Pero, formarse profesionalmente es para estar en condiciones de investigar críticamente los problemas que otras personas ven como evidentes. Es allí donde está la identidad que debe ser de reconocimiento por la sociedad.

El desarrollo capitalista y una mayor especialización dentro del campo de las ciencias, históricamente ha hecho que surgieran nuevas profesiones como es el caso de la sociología. Al respecto Sinesio López (1990:40) afirma que todo esto obedecía a razones como: "el desarrollo significativo del campo intelectual y de las ciencias en general. La modernización capitalista y cultural que produce una mayor especialización y un mayor desarrollo de las ciencias (...) una división del trabajo intelectual cada vez más significativa. Frente a los intelectuales más tradicionales (curas, abogados, médicos, filósofos) aparecen las carreras técnicas relativamente diversificadas, se desarrollan las ciencias, especialmente las ciencias sociales, y aumentan los artistas y los literatos como profesionales, ya no como aficionados".

Hasta antes de la institucionalización de la Escuela de Sociología, el análisis de estos problemas que afrontaba el país estuvo a cargo de profesionales de otras disciplinas y no de sociólogos. Están los literatos, ingenieros como Carlos Malpica que escribe su libro "Los dueños del Perú", Francois Bourricaud (antropólogo), con su investigación sobre "Poder y Sociedad en el Perú", José Matos Mar sobre "las Barriadas en Lima”, entre otros. Asimismo, las corrientes literarias como la social realista estaban interesadas por la ciudad moderna, a partir de la migración. Ingenieros, antropólogos, literatos desde su perspectiva profesional enfatizan en el tema urbano, privilegiando la visión de las barriadas. Donde el personaje principal es el migrante que llega a una ciudad deshumanizadora como es Lima. Es decir, todos ellos levantan su voz de protesta. Desde la literatura, es importante mencionar a los narradores, poetas y críticos en la década de los 60 , quienes fueron testigos de una sociedad víctima de la represión y ánimo político exacerbado. El triunfo de Acción Popular con Femando Belaúnde Terry (19631968), El surgimiento de la guerrilla del 65 y la muerte del poeta Javier Heraud (Puerto Maldonado, 1963), el golpe militar en 1968 con el General Juan Velasco Alvarado. Otros hechos internacionales que marcaron la década fueron la Revolución Cubana, la guerra de Vietnam y el movimiento estudiantil europeo, la guerra fría, la revolución cultural China con Mao. Asimismo, estaba el movimiento del hipismo, la revolución sexual, el surgimiento de los movimientos feministas y estudiantiles que trataron de imponer un nuevo estilo de vida. Eran los ańos en que se miraba con apasionamiento el cine del neorrealismo italiano y las películas de Buñuel. Se escuchaba a The Beatles, The Rolling Stones, Bob Dylan, Joan Baez, Violeta Parra, etc. Además de las películas y novelas mexicanas. 


\section{Demanda de sociólogos durante el militarismo (1968-1980)}

Han pasado más de cinco décadas, desde la creación de la Escuela de Sociología como profesión y definitivamente, la sociedad ha cambiado, pero el malestar de los padres cuando sus hijos deciden estudiar esta carrera aún continúa. A pesar de que hoy en día todos hablan de sociólogos. El lenguaje sociológico es parte del habla popular. Las personas saben por qué la gente es pobre y otros son ricos, saben por qué la gente migra a las ciudades, que existen grupos de poder que nos dominan; comprenden y analizan la coyuntura política nacional y utilizan muchos conceptos sociológicos con naturalidad, sin preocuparse por su naturaleza y definición.

En la década del 1960, nuestra formación en el Ciclo Básico o de Cultura General de la Facultad de Letras de la Universidad Nacional Mayor de San Marcos, fue fundamentalmente humanista, en un contexto nacional e internacional en que se vivía, sentaron las bases en nuestra formación personal y profesional, principalmente para los que veníamos de las zonas andinas con una cultura de solidaridad y reciprocidad. En ese sentido, destacados maestros de la Facultad de Letras nos formaron con ética, valores y de servicio a nuestro país. Es importante destacar a nuestros profesores de filosofía, historia, lengua y literatura, psicología, antropología que trasmitían sus conocimientos con tanta elocuencia que a pesar de la incomodidad de los asientos uno no sentía el cansancio en escucharlos. A esto hay que agregar los debates políticos en las aulas de la Facultad, donde algunos dirigentes se distinguían por su casaca de cuero y la barba crecida.

Bajo la dirección de nuestro profesor de literatura el Dr. Francisco Carrillo se funda Haraui, la revista de poesía de más larga duración en la historia de la literatura peruana, y que fundó la publicación en homenaje a Javier Heraud, No podemos dejar de mencionar a la nueva generación de poetas como Carmen Luz Bejarano, Antonio Cisneros, Rodolfo Hinostroza, Marco Martos e Hildebrando Pérez Grande. Asimismo, el grupo de jóvenes narradores que se unen en 1966 para crear la revista Narración liderados por Miguel Gutiérrez y Oswaldo Reynoso. Aparte de Mario Vargas Llosa los narradores que integran está: José Antonio Bravo, Alfredo Bryce Echenique, Antonio Gálvez Ronceros, Miguel Gutiérrez, Gregorio
Martínez y Edgardo Rivera Martínez. Todos ellos, le dieron a sus obras un contenido contestatario y de compromiso social.

Con respecto a la literatura latinoamericana, florece el llamado "boom latinoamericano" y, los nombres de escritores que comienzan a sonar son Gabríel García Márquez de Colombia, José Lezama de Cuba, José Donoso de Chile, Carlos Fuentes de México, Julio Cortázar de Argentina, Juan Carlos Onetti de Uruguay y Mario Vargas Llosa de Perú, entre otros. Este interés por lo latinoamericano no fue casual, sino que se impone la revalorización de una literatura que había comenzado a retratar el mundo americano con su propia técnica y lenguaje. En esta muestra, está presente Mario Vargas Llosa que con la frase que él pone en boca de su personaje Zavalita “¿En qué momento se había jodido el Perú?" en su, novela "Conversación en la Catedral" demuestra que siguen vigentes los problemas del Perú y que si no reflexionamos y conocemos nuestra historia estamos irremediablemente condenados a revivirlos.

En el campo de la crítica literaria estaba el profesor sanmarquino Antonio Cornejo Polar que con sus apreciaciones y aportes en la creación de una teoría literaria hispanoamericana abrió la veta para las nuevas generaciones de profesores. Finalmente, no podemos dejar de mencionar a Julio Ramón Ribeyro, Alfredo Bryce Echenique, juntos con Mario Vargas Llosa, cruzan las generaciones de los 50 y de los 60 , y siguen siendo protagonistas en los 70 , en los 80 , en los 90 y los dos últimos hasta en el presente milenio. Los jóvenes universitarios de la década del sesenta, fuimos apasionados lectores de la mayoría de estos textos, que van a ir configurando nuestra identidad, sensible, romántica, de compromiso y de rebeldía frente a toda forma de dominación.

Finalmente, vendrían las lecturas de autores mucho más especializados, tanto de la generación del novecientos y del centenario: Francisco García Calderón, Manuel Gonzales Prada, Víctor Raúl Haya de la Torre, José Carlos Mariátegui, Víctor Andrés Belaunde, Jorge Basadre, además de los clásicos de la sociología como Weber, Durkheim y Marx, que consolidaron nuestra manera de ver la sociedad y el mundo, que hasta la actualidad sigue siendo la matriz de nuestra identidad, a pesar de que vivimos en una época diferente, a decir de muchos, en una "sociedad posmoderna", "sociedad del conocimiento" o de la "tecnología, información y comunicación". 
La construcción de nuestra identidad profesional, es un tema que supone examinar su multidimensionalidad, puesto que abarca aspectos biológicos, psicológicos, sociales y culturales; implica la forma en que cada persona se concibe en diferentes ámbitos, por tanto se asume que la identidad es dinámica y progresiva (Ericson, 1968, Marcia, 1980, Turner, 1982 y Tajfel, 1981). Asimismo, son importantes las interacciones en las que se está inmerso el sujeto, ya que estas le dan sentido a la identidad (Turner et al, 1987), citado por Ruvalca-Goyaso (2011). Principalmente es un sistema de valores, creencias, actitudes, comportamientos y un modo de actuar en el espacio donde uno se encuentra. Es aquí donde uno manifiesta frente a los demás de manera distinta, ya sea la familia, el trabajo, la iglesia, en constante y mutua interacción. En resumen, la construcción de la identidad es el resultado de diversas influencias: el contexto social, cultural, ideológico, económico y político que son referentes ineludibles y el aspecto personal en cuanto a lo cognitivo, afectiva y moral,

Hay que tener en cuenta que la sociedad es dinámica y se dan hechos que van configurando cada etapa de nuestras vidas. Es una especie de matriz en nuestras conductas. De donde la identidad no es una esencia inherente al individuo o un elemento externo e impuesto a la conducta del sujeto, sino que es un proceso en constante reconstrucción y que puede ser comprendido a partir del comportamiento y de la interacción de las personas con los demás ya sea individualmente o colectivamente. La identidad es la percepción que tenemos cuando interactuamos en los diferentes contextos del llamado mundo del trabajo o de la vida cotidiana.

Se partió del presupuesto de que la identidad profesional de los sociólogos egresados de la Universidad Nacional Mayor de San Marcos, durante estas décadas de cambio y de conflicto enfrentó etapas de crisis y de reconocimiento, según los cambios en el modo de ser de la sociedad, de la universidad y la interacción con los compañeros de clase. Para estos profesionales en principio fue difícil insertarse en la esfera laboral, debido principalmente al desconocimiento de sus capacidades de trabajo concretas por parte de los empleadores, pero también a la falta de reconociniento en la sociedad, igual que de los médicos, contadores, ingenieros, etc. En este proceso de construcción de la identidad ha tenido mucho que ver también la extracción social familiar y territorial, el vínculo entre la formación escolar y universitaria, es decir, las diversas asignaturas impartidas, los docentes, compañeros de aula, lecturas de obras científicas, ensayos, obras literarias; además de la adquisición de experiencias prácticas acerca de los hechos que ocurren en la sociedad que retroalimenten a la dinámica académica. La procedencia familiar con sus opciones políticas y/o religiosas, condiciones económicas y sociales, son factores determinantes en la construcción de la identidad profesional. Los que hemos sido docentes por muchos años y que permanentemente hemos interactuado con los alumnos y egresados, siempre fue una preocupación en conocer a cada uno de ellos como personas y su procedencia para comprender sus dificultades y éxitos en su formación académica y profesional y al momento de enfrentarse al mundo del trabajo. Según testimonio de los mismos egresados, ellos tuvieron que afrontar muchas dificultades ya sea por razones de procedencia familiar, de universidad de donde habían egresado, falta de dominio de algún idioma extranjero, pero principalmente por desconocimiento de parte de los empleadores acerca de su actividad ocupacional. ¿Qué saben hacer los sociólogos? Eso era la pregunta frecuente. Por este desconocimiento las instituciones en muchos casos las vinculaban con tareas ajenas al quehacer sociológico. Aún en la actualidad se les confunde con otras profesiones como trabajo social, antropología, psicología social, administración o ciencia política.

Cuando la Junta Militar de Gobierno con Velasco Alvarado asume el poder en 1968 e impulsa un conjunto de reformas radicales con el propósito de romper con el estado oligárquico, modernizar la economía y promover el desarrollo nacional, para los sociólogos de las primeras promociones mayoritariamente provinciana fue positivo la liquidación de la oligarquía y los terratenientes que por siglos habían oprimido a los campesinos. Además, fue una oportunidad para insertarse profesionalmente en los distintos espacios que ofrecía este proceso de cambio en el gobierno y la sociedad. Este proyecto implicaba una fuerte intervención del Estado y al mismo tiempo, una movilización organizada de la población, al margen de los partidos políticos. Este nuevo carácter ideológico del nacionalismo de la Junta Militar de Gobierno, consistió en un programa de reformas de carácter antioligárquico, nacionalista y antiimperialista (primera fase). En su programa afirman que estas medidas iban encaminadas a poner fin al caos económico, a 
la inmoralidad administrativa, a la improvisación, al entreguismo respecto a las fuentes naturales de riqueza y a su explotación en beneficio de grupos privilegiados, así como a la pérdida del principio de autoridad y a la incapacidad para realizar las urgentes reformas estructurales que reclama el bienestar del pueblo peruano. Plantea como su objetivo final la construcción de una democracia social de participación plena cuyos elementos esenciales son: a) un sistema político participativa apoyado en las bases populares; b) un sistema económico pluralista basado en un prioritario sector de propiedad social; c) un sistema social sustentado en un conjunto de comportamiento y valores morales que enfaticen la justicia, la libertad, la participación, la solidaridad, la creatividad, la honradez y el respeto por la dignidad de la persona humana (Dominguez: 2016). Estos cambios estructurales en la sociedad permitió que las primeras promociones de sociólogos empezaran a incorporarse a las instituciones gubernamentales ya sea como investigadores, analistas, planificadores sociales, promotores de programas de desarrollo, así como asesores en asuntos relacionados a la familia, la comunidad, los campesinos, obreros entre otros.

Es en este contexto que la sociología se convierte en una disciplina privilegiada, por cuanto se abren varios ámbitos de intervención profesional. El primero y fundamental es el espacio académico, científica, el de la docencia universitaria; pero también está los espacios del sector público como el Instituto Nacional de Planificación (INP), los Ministerios, el Sistema Nacional de Apoyo a la Movilización Social (SINAMOS), Oficina Nacional de Cooperación Popular, Fondo de Cooperación al Desarrollo (FONCODES), el Centro Nacional de Capacitación e Investigación para la Reforma Agraria ( CENCIRA), Organizaciones no Gubernamentales ONGs, Estas instituciones fueron los principales receptores de los egresados de la Universidad Nacional Mayor de San Marcos.

La Cooperación Popular fue otro espacio de trabajo y de aprendizaje para los sociólogos de las primeras promociones. Es a través de este programa que muchos de ellos se reencuentran y vinculan con el mundo rural y campesino, y conocen de cerca las diversas problemáticas que históricamente venían afrontando los pobres del campo. Pobres que históricamente sufrían la dominación colonial durante el virreinato y la república, los indígenas son víctimas del sometimiento y la explotación de parte de los terratenientes que se habían apropiado de sus tierras comunales.

Este programa se crea con la finalidad de mejorar los niveles de vida de este sector de la población. Programa que se mantiene perenne en la conciencia y existencia del poblador peruano, debido a su carácter ancestral; ya que puede ser entendido como una coexistencia de dos culturas; la del imperio incaico con la moderna, donde se han dado esta fusión o mezcla en la que ha quedado y queda la influencia de una cultura sobre la otra. Debido a que varios elementos al incorporarse dan resultados positivos en su aplicación como solución a las dificultades de las poblaciones rurales y marginales. Se construyó minicentrales hidroeléctricas en los distritos rurales; se desarrolló pequeñas empresas artesanales y unidades productivas con la finalidad de generar empleo permanente; programas micro regionales de desarrollo rural integral; mejorar los niveles alimentarios de las comunidades deprimidas; generar oportunidades de ocupación temporal en el marco del servicio comunal de apoyo al empleo; estimular la participación de los pueblos y comunidades rurales y Urbano Marginales del país, mediante distinciones y recompensas; $y$, finalmente, alentar las iniciativas y creatividad de las comunidades mediante programas de capacitación que haga posible la creación, adecuación y transferencia de tecnología intermedia. Todo este conjunto de programas exigía la participación activa de los científicos sociales en general y de los sociólogos en particular, no sólo para realizar los estudios sociales, sino también en la ejecución de las programas.

Otro espacio de trabajo para los sociólogos de las primeras promociones fue el CENCIRA. Centro que se crea durante el Gobierno Militar del Gral. Velasco. Los sociólogos participaron activamente haciendo diagnósticos e investigaciones acerca de la problemática rural. Cuando Velasco lanzó su reforma agraria en 1969, reconocía que eliminar las grandes propiedades y crear cooperativas iba a requerir un gran apoyo, a fin de evitar una caída seria de la producción y, más aún, incrementar la producción de acuerdo a las demandas nacionales. El Gobierno tenía interés en obtener asistencia para la reforma agraria, y un especialista de la FAO en reforma agraria, que estaba trabajando en Chile. Ayudó en la formulación tanto del CENCIRA como de un proyecto PNUD/FAO. Aquí de hecho la presencia de profesionales de la sociología y otras disciplinas como economía y la antropología fue sumamente importante 
y pertinente. Estos profesionales se enfrentaron a una enorme cantidad de actividades como la orientación y capacitación a fin de que los beneficiarios de la reforma agraria aprovecharan al máximo las oportunidades ofrecidas. Los diagnósticos y las investigaciones dieron cuenta acerca de campesinos de bajo nivel educativo, acostumbrados a sólo obedecer órdenes, para la aplicación de la Reforma Agraria, había que capacitarlos en el manejo de las cooperativas de las cuales eran miembros beneficiarios. Cambiar su percepción sobre el papel que debían asumir en la vida económica del país. Pues había necesidad de que adquirieran nuevos niveles de conocimiento y capacitación. En ese sentido, el Departamento de Comunicación del CENCIRA y el componente del proyecto PNUD/FAO diseñado para su fortalecimiento, fueron creados para ocuparse de la orientación, movilización y capacitación de la población rural. Al respecto, es importante el testimonio de Carlos Delgado Olivera (antropólogo): "En octubre de 1970 viajé a Lima a seguir cursos de "Sociedad y Culturas Campesinas" y "Métodos y Técnicas de Investigación Social”, en el flamante Centro Nacional de Capacitación e Investigación para la Reforma Agraria (CENCIRA). Egresamos de ese curso conociendo técnicas de Encuesta Participación y otros métodos en boga a base de las propuestas del brasileño Paulo Freire que, después de tantos años, sigo pensando que son los que mejor se ajustan para ser aplicados en nuestra compleja realidad de países subdesarrollados (Delgado: 2014)".

Otro espacio importante para la inserción laboral de los sociólogos fue el Sistema Nacional de Apoyo a la Movilización Social (SINAMOS) ${ }^{2}$. En 1971 funcionaba aún la Corporación de Fomento y Desarrollo Económico de Tacna COFDET. Carlos Delgado, conjuntamente con un alto directivo de ella de COFDET y el Coordinador de la Oficina Local de Desarrollo de Pueblos Jóvenes viaja a Lima para participar del Primer Seminario Informativo del SINAMOS. Según confesión de parte. "En una ceremonia solemne se inauguró el Seminario en Huampaní, el 8 de diciembre de 1971. El auditorio estaba repleto de delegados de todo el país. Presidía la mesa directiva el General Leonidas Rodríguez Figueroa militar que, con el grado de Coronel, había conspirado con Velasco Alvarado. Lo acompañaba, a su diestra, el doctor Carlos Delgado Olivera y a la siniestra el

Wikipedia coronel Oscar Torres Llosa, personaje de segundo orden pero de gran participación en las campañas de adoctrinamiento y concientización de la población ${ }^{3}$.

Cuando en 1972 se crea el Sistema Nacional de Apoyo a la Movilización Social -SINAMOS- fue con la finalidad de movilizar organizadamente a la población y controlar las movilizaciones sociales. Organismo que sirvió como conector entre las masas populares y el gobierno militar. Para ello, además de su aparato burocrático, utilizó asociaciones visibles con lo popular. El encargado de ponerla en marcha fue el general Leónidas Rodríguez Figueroa, quien estuvo fuertemente identificado con un marcado socialismo. La idea consistía en llegar a concientizar -a través de esta organización - a los pobladores de barrios marginales y juventudes, sobre todo, de las virtudes de la revolución; por esto se tomaron en consideración: las organizaciones juveniles, las organizaciones laborales, las organizaciones rurales, las organizaciones de pueblos jóvenes y zonas de subdesarrollo urbano interno, las organizaciones económicas de interés social y las organizaciones culturales y profesionales.

Pues, este proyecto permitió una mayor incorporación de profesionales sociólogos para cumplir con esta labor principalmente en los sectores marginales del país. Algunos analistas han calificado como la década del reconocimiento de la sociología como oficio y profesión, en su papel de "ingeniería social". A todos estos sectores iba dirigida la llamada "capacitación", pues lo que se les hacían escuchar eran las bases ideológicas de la "revolución", sin posibilidad de cuestionarlas, lo cual contradecía abiertamente el objetivo que se afirmaba tenía el SINAMOS de "estimular la creación y el desarrollo de instituciones sociales autónomas y auténticamente participativas, vale decir, realmente democráticas y no manipulables [...]". Quien hacía demasiadas preguntas u objeciones en las reuniones de "capacitación" era inmediatamente objeto de hostilidad y persecución. La participación de los sociólogos en la concientización, así como la dominación ideológica militar los distanció de aquellos que estaban en contra de este proceso reformista, principalmente de los grupos radicalizados como Patria Roja,

3 Carlos Delgado Olivera, el sociólogo mentor del SINAMOS, había sido en una época un discípulo predilecto del líder y fundador del APRA, Víctor Raúl Haya de la Torre. Decían que era considerado uno de los delfines formados por el viejo político. Juan Vicente Requejo, un periodista norteńo, que después fuera uno de los primeros Decanos del Colegio Nacional de Periodistas, dijo que todos conocían a Delgado Olivera con el apodo de "Calín". 
Bandera Roja y Sendero Luminoso entre otros que existían en los años setenta.

Los científicos sociales y especialmente los sociólogos entraron a trabajar con fuerza en las áreas laboral, campesina, juvenil, cultural, vecinal y de pueblos jóvenes. La intención era no dejar ningún campo de la actividad nacional, ninguna organización, fuera del alcance de la burocracia estatal que empezaría, por toda la república, a vender la idea de lo que era el SINAMOS. Se copiaron modelos cubanos de propaganda. Uno de los afiches que decía: "SINAMOS ERES TÚ" sintetizaba el deseo del gobierno revolucionario de la Fuerza Armada de abarcar a todos los peruanos y comprometerlos dentro de las fronteras de la organización destinada, en primer término, a difundir la confusa ideología de la revolución que pregonaba no ser capitalista ni comunista y que tendía, según sus ideólogos, a buscar la participación plena de los ciudadanos en una también confusa democracia social. En realidad era un conjunto de ideas y de propuestas entre las que se mezclaban los aportes de la social democracia con los del marxismo y el trotskismo. No en vano, entre los jóvenes líderes, se encontraban apristas y marxistas.

En la Confesión de parte, Carlos Delgado dirá al final de su participación en el Gobierno Militar lo siguiente: "La experiencia llamada SINAMOS nos marcó por algún tiempo. Para mí fue una gran decepción y una prueba de que las "revoluciones" no se hacen de arriba para abajo, por decretos, así se cuente con todo el poder en lo económico, lo político y lo militar. Éramos jóvenes y como todos los jóvenes idealistas, hasta ingenuos. Muy pronto nos habíamos decepcionado de los ¿partidos tradicionales?. Habíamos bebido la rebeldía de los años 60. Nos entusiasmamos con los barbudos cubanos, de la primera época. Sentimos como propias las rebeldías de los jóvenes franceses y de los argentinos que con sus protestas conmocionaron el mundo. Ingresamos a la vida ciudadana, apenas egresados de la Universidad, cuando en varios países de América gobernaban partidos de izquierda. Creímos que ese era el camino. Nos equivocamos, nos frustramos. No sería la primera ni la última vez" ${ }^{\prime}$. Es importante señalar que al igual que SINAMOS, se crean otros organismos que jugarán el mismo papel que éste. Por ejemplo en el sector campesino se crea por Ley la Confederación Nacional

4 Confesión de parte. Ibid.
Agraria (CNA); en el sector obrero la Central de Trabajadores de la Revolución Peruana (CRTP); en el magisterio el Sindicato de Educadores de la Revolución Peruana (SERP), etcétera. Estas organizaciones, la igual que la instrumentación política para reformular la organización de la sociedad alrededor de un aparato corporativo que debía congregar la unidad nacional bajo el comando militar, fracasaron estrepitosamente, desde sus inicios.

A modo de resumen diremos que el amplio programa de reformas implantado por el gobierno del General Juan Velasco Alvarado, estaba destinado a estructurar un nuevo modelo de acumulación y establecer las bases de un nuevo sistema de dominación política. Para lograr este objetivo, que ayudará a superar al mismo tiempo las barreras que habían anquilosado el desarrollo económico, se llevó a cabo la construcción de un poderoso sector estatal que, asociado con el capital internacional, acelerará la acumulación de capital y permitirá la inserción dependiente del país en un nuevo nivel de la división internacional del trabajo del mundo capitalista. Esta experiencia de una nueva forma de dominación y acumulación capitalista, fue sumamente interesante no sólo como reflexión teórica en los espacios académicos, sino fundamentalmente la participación de los profesionales sociólogos en los diversos espacios de investigación, planificación y gestión.

A partir del año 1975, el endeudamiento externo y la crisis económica que estalló, truncaron el proyecto reformista de la Junta Militar. La movilización sindical y popular que culminó en el Paro Nacional del 19 de julio de 1977, empujó el retorno a la democracia representativa, mediante la convocatoria a una Asamblea Constituyente, la aprobación de una nueva Constitución y la realización de elecciones, hecho que también es punto de partida de la violencia política desatada por Sendero Luminoso y el MRTA. La demanda de profesionales de las ciencias sociales fue cada vez menos, principalmente a partir de la década del ochenta.

\section{Mercado laboral entre la tensión y la violencia.}

Hemos señalado en las páginas anteriores que la identidad profesional es multidimensional. Entonces, el otro componente es la malla curricular que diseña la Escuela encargada de formar profesionales. En ese 
sentido, en el caso de la Universidad Nacional Mayor de San Marcos, se mantuvo un Plan de Estudios de los años setenta hasta 1987. O sea, en los primeros años de profesionalización fue el positivismo como fundamento epistemológico y teórico, para luego pasar en la década del 70 a una orientación de corte ideológico militante a través de cursos básicos como el Materialismo Histórico y Dialéctico. Es sólo a partir de mediados de la década del 1980 que se reorienta con un enfoque más profesionalizante que ideológico, luego, en las décadas siguientes se hacen algunos reajustes en el plan de estudios, en concordancia con la situación de crisis económica, social y política que se vive en el país, hacia una visión fenomenológica y de la complejidad con marcada tendencia hacia la tecnología económica y el liberalismo político. En este marco, son otros los temas de preocupación incluso desde la academia, como la democracia y se abandonan las grandes miradas totalizadoras, optando por realizar análisis más concretos sobre situaciones de coyuntura.

No podemos dejar de mencionar que otro componente que les dio identidad a los sociólogos fueron los medios de comunicación. A raíz de la presencia de los grupos radicalizados en la universidad, difundieron en la población una imagen negativa acerca de los estudiantes y docentes. Se presentó en los medios muchos reportajes acerca de la presencia y actividades de Sendero Luminoso, afirmando que las "Facultades se habían convertido en escuelas de adoctrinamiento terrorista y que esto se podía comprobar a través de los syllabus de las asignaturas". Lo que permitió que en el imaginario de la población los estudiantes, así como los egresados de sociología sean considerados como pertenecientes a Sendero Luminoso, comunista, socialista entre otros adjetivos. Las empresas cerraron las puertas, así como también las instituciones públicas. Fueron pocos, los que a través de las relaciones personales lograron incorporarse como profesionales y demostrar que no eran lo que la sociedad en su conjunto había construido en su imaginario frente a los estudiantes y egresados de la Escuela de Sociología.

Tanto docentes y alumnos, tenían mayoritariamente una visión ideológica de izquierda, entendiéndose por ello como el compromiso intelectual y manual con los sectores pobres y una sociedad justa, libre y de verdadera democracia. Por ello, siempre estaban presentes al lado de las organizaciones populares que se movilizaban por las calles de Lima, reclamando sus derechos, contra la represión policial y las nuevas formas de dominación colonial. Venciendo las amenazas de Sendero Luminoso, tanto docentes y alumnos, permanentemente manifestaron su contundente rechazo a los crímenes cometidos por Sendero Luminoso y el MRTA y las Fuerzas Armadas. Pero, los debates políticos e ideológicos en las aulas y auditorios de las facultades, con aquellos estudiantes que simpatizaban con el fundamentalismo maoísta, no eran conocidos por la sociedad, sino la prensa presentaba principalmente los momentos de incursión de Sendero para realizar sus prédicas ideológicas en los espacios de la universidad.

En estas condiciones, las instituciones públicas y privadas, asumieron una actitud de rechazo a los estudiantes de la Universidad de San Marcos y una restricción total para el empleo, cuando alguna empresa solicitaba profesionales en los periódicos señalaban de qué universidad tenían que ser egresados. Asimismo, muchos alumnos fueron retirados por sus padres o los mismos alumnos optaron por irse a otras universidades, pero para estudiar otra especialidad. Varias universidades cerraron las Escuelas de Sociología a falta de alumnos. Esto, motivado por las condiciones de inseguridad frente a su futuro profesional y las condiciones difíciles en que se encontraba el espacio académico por la presencia de los grupos violentistas, así como la presencia de los militares y el servicio de inteligencia; además de las huelgas prolongadas de los administrativos y docentes de la universidad. Agregándose a todo esto, principalmente el abandono de las universidades públicas por parte de los gobiernos de turno, que en vez de incrementar los presupuestos, fueron en descenso. Las autoridades no podían atender los servicios indispensables como son las bibliotecas que se encontraban desactualizadas, laboratorios obsoletos, servicios higiénicos en condiciones deplorables, carpetas inservibles, aulas sin fluorescentes, trámites para el bachillerato y la licenciatura que demoraban años, etc., etc.

\section{Experiencia ocupacional del sociólogo en el sector público y privado hoy}

La crisis económica generalizada, la violencia terrorista por más de una década, la deslegitimación de los Partidos Políticos y la corrupción generalizada, permitió un conjunto de cambios en los planes de 
formación académica del profesional sociólogo, así como el deslinde con los discursos provenientes del marxismo-leninismo, maoísmo, asumiendo una tendencia profesionalizante de la sociología. En este sentido, los destinos laborales de los sociólogos se han ido diversificando hacia el sector privado y las asociaciones civiles, además de continuar en la docencia universitaria y en el sector público.

Tal como hemos señalado vivimos en una nueva sociedad, calificado por muchos intelectuales como la sociedad "posmoderna", de la "cuarta revolución industrial" o "sociedad del conocimiento", entre otros. Cualquiera que sea el nombre de esta nueva sociedad, lo real es que nuestras relaciones sociales, culturales, económicas y políticas y así como nuestra vida cotidiana y la intervención profesional en las instituciones están cambiando con mucha rapidez. Posiblemente, el mercado laboral es uno de los planos donde más cambios acelerados se están dando. Bueno, hasta ahora seguimos preguntando a nuestros hijos ¿Qué vas a ser cuando seas mayor? Sin saber ni nosotros mismos, qué profesiones requerirá la sociedad en el futuro inmediato. Dentro de algunos años, muchas profesiones desaparecerán y otras nuevas surgirán como resultado de los procesos de cambio a nivel global. Hoy en día muchos de los egresados de Sociología enfrentan en su quehacer laboral nuevas tareas y actividades que al momento de ingresar para estudiar esta carrera profesional no se imaginaron, pero tampoco los planes de estudio no estaban pensados futuristamente.

La sociología en el Perú durante estas dos últimas décadas, poco a poco ha ido superando las dificultades que tuvo que afrontar los primeros treinta años de su vida institucional. Las instituciones que emplean a sociólogos han entendido que la sociología es una profesión necesaria, pertinente en los distintos espacios, no sólo como técnicos en planificación o en la solución de las relaciones comunitarias entre las empresas y los actores, cuando entran en conflicto de intereses; sino principalmente, por su visión aún totalizadora a través de la investigación y el análisis crítico de la coyuntura, pueden orientar mejor la marcha de las instituciones tanto públicas como privadas. Es evidente que por su cada vez mayor reconocimiento y legitimidad es requerido a nivel nacional y local: ministerios, Organismos descentralizados, gobiernos regionales, locales, empresas públicas, privadas, consultoras entre otras, hoy por hoy, el licenciado en sociología, si bien tiene más espacios ocupacionales, pero para algunos las condiciones de contratación aún no son tan favorables para su realización como persona, familia y profesionalmente. Como hemos señalando, el sector público es el principal destino de desempeño profesional, pero también está la industria de la construcción, el comercio, el transporte, las telecomunicaciones, servicios bancarios, servicios financieros, seguros y el sector salud.

En un contexto de globalización y la revolución tecnológica, donde los cambios en la sociedad son tan rápidos, es un reto para las universidades que forman profesionales, en hacer un trabajo permanente de cambios curriculares y de perfeccionamiento de sus docentes, para que oportunamente puedan dar respuesta a cada uno de los retos y desafíos de la sociedad. Como se podrá ver el marco de referencia indispensable para comprender el proceso de construcción de la identidad en parte está en la malla curricular con la cual se han formado académica y profesionalmente y el segundo componente es el ámbito laboral, principalmente en la inserción al mercado de trabajo, puesto que este primer enfrentamiento posibilita un choque de concepciones entre la idea de lo que es un sociólogo y lo que se demanda en la práctica concreta dentro del empleo, es decir, entre las formas identitarias para sí y para el otro.

Aquí presento, experiencias de trabajo de algunos de los sociólogos que luego de su inserción como practicantes y luego profesionalmente, han ido definiendo su identidad de sociólogo profesional. Cada una de las experiencias, nos dan cuenta que no fue fácil, insertarse al mercado laboral y tuvieron que pasar por muchas instituciones y capacitarse ya sea a nivel de posgrado y cursos de perfeccionamiento que les permita un adecuado manejo teórico e instrumental en su desempeńo profesional. A cada uno de ellos se les solicitó vía internet acerca de su experiencia en cuanto trayectoria laboral y capacitación, después de egresar de la universidad.

Carlos: Nació en Lima, pasó su infancia durante los ańos difíciles de la segunda etapa del militarismo de la década del setenta y la crisis económica de la década del ochenta. Cursó sus estudios de primaria en un colegio parroquial y la secundaria en el Colegio Nacional Nuestra Señora de Guadalupe. Sus padres, ambos sociólogos formados en la Universidad Nacional Mayor de San Marcos, no veían con simpatía que estudiara la misma profesión. A pesar de estar preparándose en la Pre de la Universidad Agraria La Molina, se presentó a 
San Marcos, con la finalidad de medir su rendimiento académico y para la sorpresa de él mismo y de sus padres terminó ingresando nada menos que a la especialidad de sociología.

Estudió entre los años 1989 y 1993. Fue uno de los primeros de su promoción en optar la Licenciatura. Luego, estudió maestría en Ciencia Política en la Pontificia Universidad Católica del Perú, estudios de doctorado en Ciencias Sociales en la UNMSM, asimismo ha sido estudiante visitante en la Universidad de Carolina del Norte en Chapel Hill. Inició sus actividades profesionales como asistente de investigación en el Grupo de Análisis para el Desarrollo (GRADE), luego pasó a trabajar en el Instituto de Estudios Peruanos como asistente de investigación y luego como investigador asociado. En la actualidad trabaja en la Oficina Nacional de los Procesos Electorales como Sub Gerente de. Asistencia Técnica de la Gerencia de Información y Educación Electoral, donde desarrolla las funciones siguientes: brindar asesoría a los partidos políticos en la organización de sus elecciones, Asesoría a universidades, colegios profesionales en sus procesos electorales, capacitación a los personeros de mesa sobre sus funciones, elaborar informes a los usuarios del servicio de asistencia técnica y sistematizar la actividad, así como brindar charlas de capacitación sobre temas electorales a las organizaciones políticas y representando a la institución cuando es requerido en otros países de América Latina.

Después de egresar de la universidad, se vio en la necesidad de capacitarse en los cursos siguientes: Curso a distancia en Gestión de los Procesos Electorales, por la Fundación CEDETT, Madrid. Curso presencial en Estadística aplicada con SPSS, en el Centro de Estudio y Promoción del Desarrollo - DESCO. Curso Taller Presencial en Educación en Derechos Humanos y Participación Ciudadana del IPEDEHP. Curso a distancia en Política, mercado y sociedad en América Latina y el Caribe a fines de Siglo. Campus virtual de CLACSO. Curso a distancia sobre Nuevas Tecnologías de información y comunicación. Campus virtual de CLACSO. Pasantía sobre "Régimen de Partidos Políticos: Prerrogativas y Fiscalización de los Recursos" en el Instituto Electoral de México, marzo, 2017.

Durante su ejercicio profesional como sociólogo ha participado en diferentes eventos académicos tanto a nivel nacional e internacional: expositor en el Taller "El papel de la sociedad civil en la reforma electoral: los casos de Panamá y Perú, con la ponencia "Potencial para la reforma electoral en el Perú", organizado por el Centro de Asesoría y Promoción Electoral - CAPEL realizado en la ciudad de Panamá, el 19 y 20 de julio de 2012. Expositor en el Seminario Internacional Atlas Electoral Latinoamericano, con la ponencia "Elecciones presidenciales en el Perú", organizado por la Corte Nacional Electoral de Bolivia y realizado en la localidad de Huatajata - Lago Titicaca, Bolivia, del 23 al 25 de noviembre de 2006. Expositor en el Taller de Investigación Trayectorias a la Sociedad Política, desarrollado el 11 y 12 de marzo de 2004 en Santiago de Chile. Expositor en el Taller Latinoamericano Sociedad Civil, esfera pública y democratización en América Latina, desarrollado del 21 y 23 de setiembre de 2003 en Xalapa (Veracruz-México)

Asimismo ha realizado un conjunto de investigaciones, cuyos resultados han sido publicados en revistas nacionales e internacionales. Entre las publicaciones más importantes está:

- 2006. «Perú: Elección Presidencial 2006» Artículo publicado en Salvador Romero Ballivián (compilador) Atlas Electoral Latinoamericano. La Paz: Corte Nacional Electoral.

- 2005. El retorno de los partidos a la democracia. Las elecciones peruanas del 2001. Osaka:

- 2004. “QQuiénes gobiernan los municipios y regiones? Perfiles de los candidatos y electos en el año 2002". Artículo publicado en la revista Elecciones, Año 3, $\mathrm{N}^{\circ}$ 3. Lima: Oficina Nacional de Procesos Electorales.

- 2004. Liderazgos en transición: trayectorias de liderazgo político en el Perú. Cuaderno de investigación social. Lima: Departamento de CCSS de la PUCP.

- 2003. "La Defensoría del Pueblo frente a la fragilidad institucional del Estado en Ayacucho". Artículo publicado en Ludwig Huber (editor) Centralismo y Descentralización en Ayacucho. Lima: Instituto de Estudios Peruanos.

- 2002. Las organizaciones políticas en las elecciones municipales de 1998 y 2002: un análisis comparativo. Documento de Trabajo N ${ }^{\circ}$ 5. Lima: Oficina Nacional de Procesos Electorales.

- 2002. "Derecho electoral municipal: un análisis sociológico de su variación en el Perú -19802002". Artículo publicado en la revista Elecciones, Año 1, $\mathrm{N}^{\circ}$ 1. Lima: Oficina Nacional de Procesos Electorales. 
CUADRO 1. MOVILIDAD OCUPACIONAL

\begin{tabular}{|l|l|l|}
\hline AÑO & FUNCIÓN & INSTITUCIÓN \\
\hline $1995-1996$ & Asistente de Investigación & GRADE \\
\hline 1996 & Asistente de Investigación & IDS \\
\hline 1999 & Consultoría & ESAN \\
\hline $1997-2001$ & Investigador Asociado y Asistente de Investigación. & Instituto de Estudios Peruanos - IEP \\
\hline $2000-2001$ & Programa de Protección a Poblaciones afectadas por la Violencia & Defensoría del Pueblo \\
\hline $2002-2004$ & Responsable de Proyectos de Investigación. & ONPE -Oficina Nacional de Procesos Electorales \\
\hline $2004-2011$ & Jefe de Área de Asistencia Técnica & ONPE \\
\hline $2011-2017$ & Subgerente de Asistencia Técnica & ONPE \\
\hline
\end{tabular}

Magaly: Estudió Sociología en la Facultad de Ciencias Sociales de la Universidad Nacional Mayor de San Marcos, entre los años 1998 y 2002, donde obtuvo su título de licenciada. Se capacitó en la Pontificia Universidad Católica del Perú. Certificado, Programa Elecciones y Partidos Políticos 2010. Realizó sus estudios de maestría en filosofía, mención Historia de filosofía, en la Universidad Nacional Mayor de San Marcos, 2005-2007.

María: Estudió la carrera de sociología en la Universidad Nacional Mayor de San Marcos, en los primeros años del dos mil y puntualiza que terminó de mamá, apenas había egresado de la universidad. En la actualidad es licenciada en sociología, especialista en elaboración de planes de desarrollo, líneas de base. Maneja técnicas cualitativas y cuantitativas, domina el ISO 9001, sistemas de certificación, como también ha realizado consultorías. En fin ha trabajado en varios temas con comunidades agrarias y organizaciones artesanales, tiene experiencia en trabajo con gobiernos regionales y/o locales. Afirma que luego de haber egresado tuvo que capacitarse, como también las distintas instituciones donde trabajó le permitió adquirir experiencia.

Posee conocimiento en elaboración y gestión de proyectos, formulación yaplicación de plan de desarrollo sostenible y endógeno-sustentable. Con experiencia en formación de actores, elaboración de módulos de capacitación, y fortalecimiento organizacional. Experta en el conocimiento del mundo andino y amazónico y trabajo entre gobiernos locales, regionales y comunidades (manejo de conflictos sociales). Cuenta con una base sólida para desempeñarme en puestos que comprometan el trabajo con diversos actores sociales, además de demostrar gran adaptabilidad a los más diversos entornos laborales.

Experiencia como consultora en relaciones comunitarias, análisis de conflictos sociopolíticos, gestión de proyectos sociales, prevención de conflictos sociales. Coordinadora de responsabilidad social, gestión de programas sociales sostenibles. Intervención con comunidades. Coordinadora del área de desarrollo. Jefa del área de organizaciones agrarias y relaciones comunitarias.

CUADRO 2. MOVILIDAD OCUPACIONAL

\begin{tabular}{|l|l|l|}
\hline AÑO & CARGO & INSTITUCIÓN \\
\hline A 2014 & Transversalización del Género en GR y GL & Ministerio de la Mujer y Poblaciones Vulnerables - MIMP \\
\hline A 2013 & Coordinadora del Programa Mujer e Inclusión Ciudadana & Jurado Nacional de Elecciones \\
\hline A 2012 & $\begin{array}{l}\text { Planificación Social. Elaboración de planes de desarrollo } \\
\text { urbano, como planificador urbano en las Provincia de } \\
\text { Cańete y Sechura (Piura) y el distrito de Majes (Arequipa) }\end{array}$ & Ecourbe Consultores \\
\hline 2012 & Coordinadora del Programa Voto Informado & Jurado Nacional de Elecciones \\
\hline 2012 & Módulo de Formación Política -enlace & Jurado Nacional de Elecciones \\
\hline 2011 & Controlador de Proyectos & Jurado Nacional de Elecciones \\
\hline 2009 & Especialista en género & Jurado Nacional de Elecciones \\
\hline 2009 & Docente contratada & Universidad Nacional Federico Villarreal \\
\hline $2007-2009$ & Coordinadora del componente de género & Escuela Mayor de Gestión Municipal \\
\hline $2001-2003$ & Seguimiento a la función congresal & Movimiento Manuela Ramos \\
\hline
\end{tabular}


David: Licenciado en Sociología (2002-2006) por la Universidad Nacional Mayor de San Marcos. Especialista:RelacionesComunitarias-Responsabilidad Social Empresarial. Estudios de Maestría en Gestión de la Inversión Social en la Universidad del Pacifico. Profesional con amplia experiencia en la gestión social desde el sector privado, desarrollando actividades de prevención y resolución de conflictos entre empresa y comunidad, supervisión y monitoreo de proyectos sociales, asimismo establecimiento de relaciones y coordinación con instituciones estatales en diferentes niveles.

Experiencia: Oficial de Gestión Social. Compañia Minera Antamina, responsable de la coordinación y relacionamiento con uno de los principales stakeholders (Comunidad) de la compañía; ante esta responsabilidad han liderado la supervisión de los diversos proyectos de inversión social que se realiza con este importante actor. Ha participado en las diversas mesas de diálogo y desarrollo que se han generado para el adecuado relacionamiento con el stakeholder asignado; en consecuencia, se mantiene un monitoreo constante y el liderazgo para el cumplimiento de los compromisos asumidos por la compañía producto de estas mesas. Líder del Área de Relaciones Comunitarias. GyM S.A. Participación como Líder del Área de Relaciones Comunitarias en los proyectos Antapaccay (expansión Tintaya, Quellaveco. Como líder del área, se generó en conjunto el diseño e implementación de estrategias de relacionamiento, el mismo que se enmarcó en un Plan de Responsabilidad Social, el cual buscó atender a diversos stakeholders en el frente externo e interno. La realización del proceso de sensibilización dentro de la organización, para alcanzar los objetivos del proyecto respecto al mantener un buen clima social como contratista principal de estos dos proyectos se logró cumplir con el compromiso asumido respecto al tema de empleo local, el cuál indicaba que el total de la mano de obra no calificada del Proyecto vendría del área de influencia, para ello se ejecutó un programa de capacitación previo al ingreso de los colaboradores locales. Recibiendo por ello el reconocimiento del cliente. Relacionista comunitario. Stracon GyM. En los dos ańos que se participó en este proyecto se pudo concretar un buen relacionamiento de la empresa con la comunidad, siendo reconocida como la empresa contratista de mayor preocupación en inversión social en la zona. Se desarrolló un Plan de Responsabilidad Social el cual involucró un trabajo de coordinación y compromiso de diversas Instituciones de la zona (Municipalidad, Frente de Defensa, Sindicatos, diversas instituciones sociales, etc)

Capacitación: Universidad del Pacífico (PE). Maestría en Gestión de la Inversión Social. Universidad de San Martín de Porres._Diplomado en Gestión Estratégica de la Responsabilidad Social, Pontificia Universidad Católica del Perú. Diplomado: Análisis, Gestión y Resolución de Conflictos Socioambientales.

Raiza: Licenciada en Sociología por la Universidad Nacional Mayor de San Marcos 2002 - 2006. Magister en Sociología, con mención en Estudios Políticos por la Universidad Nacional Mayor de San Marcos, colegiada, con Diplomados de especialización en docencia para la formación y la capacitación, Diplomado en salud pública y responsabilidad social inclusiva, en la Pontificia Universidad Católica del Perú.

Experiencia: Coordinadora de Responsabilidad Social Empresarial. Grupo Graña y Montero (GyM S.), Proyecto Las Bambas, Apurímac. Cargo: Coordinadora del área de capacitación y responsabilidad social del Proyecto las Bambas. Relacionista Comunitaria. GyM S.A. Relacionista Comunitaria, en Proyecto «Ampliación y Mejoramiento de los Sistemas de Agua Potable y Alcantarillado para el esquema Pariachi.» Relacionista Comunitaria. Ministerio de Cultura. Cargo: Relacionista Comunitaria, en Huánuco y Huaraz. Facilitadora de Animación Sociocultural. Casa Taller Grupo Veraz. Facilitadora de talleres. Docente e Investigadora. Universidad Peruana Cayetano Heredia. Cargo: Docente - Investigadora. Facultad de Ciencias y Filosofía/ Facultad de Medicina/ Facultad deEnfermería / Facultad de Estomatología. Coordinadora, monitora y facilitadora de proyectos sociales. Fondo mundial (Cedro -impacta-Cepesju-amistad y respeto). Cargo: Coordinadora, monitora y facilitadora de actividad de la provincia constitucional del Callao. Monitora y facilitadora de Proyectos Sociales. Centro de Estudios de Problemas Económicos y Sociales de la Juventud. Cargo: Monitora y facilitadora de proyectos sociales. Cursos de capacitación: Formulación y evaluación de proyectos sociales bajo el enfoque del SNIP. Curso de especialización en Relaciones Comunitarias. Curso de especialización en Resolución de Conflictos Socio ambientales. Curso de especialización en Gerencia Social. 
Carlos: Licenciado en Sociología por la Universidad Nacional Mayor de San Marcos, 1998 - 2002. Estudios de Maestría Sociología Mención en Desarrollo Social, 2007 - 2013 y Diploma de Especialización en Diseño y Gestión de Proyectos Sociales, Trabajo Social. 2006 - 2006 en la Pontificia Universidad Católica del Perú. Estudios de Maestría de Sociología (Mención Desarrollo Social) en la misma casa de estudios. Colegiado y habilitado por el Colegio de Sociólogos del Perú (CSP 2359). En el área de Monitoreo y Evaluación, ha diseñado, validado, aplicado herramientas de Monitoreo y Evaluación de proyectos de diversa índole. En el área social y educativa, ha laborado por más de diez años en Organizaciones No Gubernamentales, que intervienen en áreas rurales y urbano-marginales, mediante la elaboración, implementación monitoreo y evaluación de proyectos de desarrollo social. Además, tiene experiencia en manejo de metodologías y técnicas de educación con participación de adultos, adolescentes, promotores de salud y educativa, líderes comunitarios. En los talleres de capacitación a participado en: Estrategias de intervención con adultos y jóvenes en Tuberculosis, VIH y SIDA y Drogas, así como de Planes Estratégicos. Por último, en cuanto al área de investigación aplicada, ha diseñado y elaborado trabajos vinculados a diagnósticos para la formulación de proyectos sociales, líneas bases y, estudios de impacto ambiental para entidades públicas y privadas, bajo la aplicación de metodologías y técnicas de corte cuantitativa y cualitativa. Además, es especialista en Monitoreo y Educación (Programa de Formación del Ministerio de Educación). Desde marzo de 2014. Seguimiento y Supervisión del Programa de Formación de Directores Subdirectores. Diseńo, Elaboración e Implementación del Plan Monitoreo y Evaluación Diseño. Elaboración e Implementación de Evaluación de Desempeño.

Hay que destacar, que el plan de estudios de la Escuela, para la formación de los estudiantes es muy general, donde los alumnos egresan conociendo un poco de todo, pero sin el dominio de nada. Precisamente, por ello, sólo cuando egresan y se insertan al mundo del trabajo se ven en la necesidad de perfeccionarse ya sea a través de maestrías, diplomados y cursos especializados que para desempeńarse con competencia en la institución, se ven obligados a realizar. Además, en la escuela no se les da las herramientas instrumentales para que puedan interactuar en diferentes campos, ya sea con las poblaciones campesinas, obreras, partidos políticos. En ese sentido, a pesar de que en los últimos ańos la currículo de la escuela es de corte profesionalizante, pero no está teniendo en cuenta las diversas actividades que realizan los sociólogos en la actualidad.

La estructura de oportunidades de los jóvenes no es estática y varía con el tiempo, tal como veremos en las páginas siguientes. No sólo está el proceso de modernización o los cambios que ocurren como efecto del proceso de globalización; sino tiene que ver con los procesos sociales y económicos que ocurren al interior del país, los cambios ocurridos durante el régimen del General Velasco Alvarado, la presencia de Sendero en los años ochenta, el gobierno de Fujimori, han sido años donde las oportunidades ocupaciones e intergeneracionales ha tenido sus propias dinámicas y particularidades. Pero, es importante, tener en cuenta que el proceso de crecimiento económico ha llevado a un mejoramiento del campo laboral para el conjunto de las ciencias sociales sin importar factores vinculados a la herencia cultural de sus hogares. En este sentido, el estudio de movilidad intergeneracional ha sido importante para valorar el progreso y cambios en las condiciones de vida a través del tiempo.

En la actualidad, la mayoría de los jóvenes que han estudiado sociología, permanentemente se capacitan, de acuerdo a la demanda de la institución donde se incorporan laboralmente. Hoy en día se puede afirmar que el sociólogo adecuadamente capacitado realiza el diseńo y la aplicación de estrategias de comunicación en todo tipo de organizaciones, los estudios de comportamiento, actitudes y opiniones de diferentes grupos sociales. A ello se ańade el estudio de viejos y nuevos problemas como la pobreza, la exclusión, la inmigración, la violencia, la desigualdad entre mujeres y hombres, la emancipación de los jóvenes o el cuidado de los dependientes. La sociología aporta una visión integral que permite diagnosticar desde una doble perspectiva cuantitativa y cualitativa los fenómenos sociales, sus tendencias y previsible evolución ${ }^{5}$. Por otra parte, es especialista en Políticas Públicas, conocedor de su diseño, gestión, planificación y evaluación con el objetivo de mejorar la calidad de vida y el bienestar de la población. Se encarga tanto de la gestión de

5 http://www.uc3m.es/ss/Satellite/UC3MInstitucional/es/ TextoMixta/1371206623194/ 
CUADRO 3. EgRESAdOS DE SOCIOLOGÍA DE LA UNMSM, POR RANGO DE EDAD, AÑO DE EGRESO, CAPACITACIÓN Y OCUPACIÓN

\begin{tabular}{|c|c|c|c|c|c|}
\hline No. & $\begin{array}{l}\text { Rango de } \\
\text { edad-años }\end{array}$ & $\begin{array}{c}\text { Año de } \\
\text { egresado }\end{array}$ & Capacitación & Centro de trabajo & Actividad que realiza \\
\hline 1 & De 35 a 50 & $1980-1990$ & Diplomado-Maestría & Defensoría del Pueblo & $\begin{array}{l}\text { Atención de quejas ciudadanas } \\
\text { contra el Estado }\end{array}$ \\
\hline 2 & De $50 a+$ & $1980-1990$ & Maestría & Universidad & Investigación y docencia \\
\hline 3 & De 35 a 50 & $2000-2012$ & Ninguna & Comerciante & No ejerce la profesión \\
\hline 4 & De 25 a 35 & $2000-2012$ & Maestría & Centro de investigación & Cuestión ambiental \\
\hline 5 & De 25 a 35 & $2000-2012$ & Seminarios & Empresa privada & Apoyo administrativo \\
\hline 6 & De 20 a 25 & $2000-2012$ & Seminarios & ONG & Gestión social \\
\hline 7 & De 25 a 35 & $2000-2012$ & Maestría & ONG & Área de Promoción \\
\hline 8 & De 35 a 50 & $2000-2012$ & Diplomado & Centro de investigación & Análisis de datos \\
\hline 9 & De 25 a 35 & $2000-2012$ & Ninguna & Ministerio Educación & Apoyo técnico \\
\hline 10 & De 35 a 50 & $2000-2012$ & Diplomado & Empresa privada & Relaciones comunitarias \\
\hline 11 & De 35 a 50 & $2000-2012$ & Maestría & Estado & $\begin{array}{l}\text { Evaluación de estudios } \\
\text { socioeconómicos }\end{array}$ \\
\hline 12 & De 25 a 35 & $2000-2012$ & Otra carrera & Centro de Rehabilitación & Educador Social \\
\hline 13 & De 25 a 35 & $2000-2012$ & Seminarios & Empresa privad & Resolución de conflictos \\
\hline 14 & De 35 a 50 & $2000-2012$ & Ninguna & Empresa privada & Relaciones comunitarias \\
\hline 15 & De 25 a 35 & $2000-2012$ & Seminarios & Ministerio & Analista social \\
\hline 16 & De 20 a 25 & $2000-2012$ & Ninguna & No ejerce & Se dedica a otra actividad \\
\hline 17 & De 25 a 35 & $2000-2012$ & Diplomado & Empresas privadas & Por contrato - analista \\
\hline 18 & De 25 a 35 & $2000-2012$ & Ninguna & Empresa privada & Supervisor administrativa \\
\hline 19 & De 25 a 35 & $2000-2012$ & Diplomado & Estado & Coordinadora programa social. \\
\hline 20 & De 25 a 35 & $2000-2012$ & Ninguna & Empresa privada & Consultoría impacto ambiental \\
\hline 21 & De 20 a 25 & $2000-2012$ & Seminarios & Empresa privada & Asistente de proyectos social. \\
\hline 22 & De $50 \mathrm{a}+$ & $1970-1980$ & Doctorado & Estado & Asesora gestión \\
\hline 23 & De $50 a+$ & $1970-1980$ & Maestría & Universidad & Docencia e investigación \\
\hline 24 & De $50 a+$ & $1970-1980$ & Seminarios & Magisterio & Profesora \\
\hline
\end{tabular}

Fuente: Encuesta aplicada en el mes de abril de 2014. Los primeros 22 se aplicó a los que asistían al curso de reactualización, organizado por la Escuela de Sociología, UNMSM.

los recursos públicos, como analizar los hábitos de la población y evaluar sus efectos.

Actualmente, los servicios profesionales de los sociólogos tienen una alta demanda en el sector público; sin dejar de lado, su creciente participación en el sector privado y en las organizaciones sociales. Desde el último tercio del siglo $\mathrm{XX}$, el sociólogo ha diversificado sus funciones. En la actualidad, los sociólogos están ocupando diversos espacios principalmente en el sector público como: Ministros de Estado, congresistas, alcaldes, Director de la Biblioteca Nacional, medios de comunicación, investigadores con prestigio internacional, asesores, consultores nacionales e internacionales, entre otros. Las perspectivas del mercado de trabajo para esta profesión apuntan hacia un incremento en la demanda por parte de empresas privadas y organizaciones sociales. De igual forma se perciben mayores posibilidades en el ejercicio independiente, ya sea de manera individual, o a través de despachos de consultoría y servicios profesionales.

Finalmente, una parte considerable del ejercicio profesional del sociólogo consiste en un trabajo de contacto directo con los actores sociales, lo que implica continuos desplazamientos tanto a nivel local, regional y nacional. Este accionar se complementa con un trabajo de gabinete o escritorio, a través del cual procesa y genera conocimientos de la realidad social. Este ejercicio implica la utilización de diversas técnicas y métodos para el acopio de información, análisis estadístico e interpretación de datos, así como de la elaboración de documentos escritos y el dominio de programas básicos de análisis cuantitativo y cualitativo 
(Vargas: 2006). En síntesis, los sociólogos ejercen su profesión en una amplia variedad de ámbitos e instituciones, desde los más clásicos como la investigación de los problemas urbanos, rurales, hasta otros más nuevos como la violencia, problemas de género entre otros.

A partir de la demanda de las empresas podemos afirmar que al igual que en otras profesiones, el campo de la sociología no es homogénea, sino que se organizan a partir de diferencias que establecen jerarquías en base a distintos criterios de legitimación. En este sentido, el corte más evidente se vincula con la separación (empírica y analítica) entre el "mundo académico" y las "prácticas profesionales" ligadas a la práctica liberal de la profesión. A continuación, nuestras hipótesis son corroboradas a través de los avisos de solicitud de profesionales sociólogos en los diversos campos ocupacionales. Hoy en día ya no es restrictivo a ciertas universidades, sino que es abierto para todos. A continuación empresas que solicitan sociólogos y profesionales afines.

Empresa San Fernando, "actualmente nos encontramos en la búsqueda de un Coordinador(a) de Responsabilidad Social, deseoso(a) de aportar y trasladar desde su experiencia y conocimientos estrategias que sumen y ayuden a cumplir con los objetivos de la organización. Requisitos:-Profesional de las carreras de Psicología, Comunicación para el desarrollo, Sociología, Economía o carreras afines".

En este caso, la empresa solicita un profesional de las ciencias sociales, que tenga conocimiento sobre temas como responsabilidad social, relaciones comunitarias, relaciones institucionales, responsabilidad social corporativa, gestión de proyectos sociales, inversión social, desarrollo sostenible. Además exigen que tenga dominio del Office, saber ejecutar proyectos de responsabilidad social bajo el modelo Triple Bottom Lime ${ }^{7}$. Conocimiento en la implementación

6 Empresa San Fernando, ciudad de Lima, 19 de abril de 2017

7 Triple Bottom line (inglés = "Triple balance") refiere a los resultados de una empresa medidos en términos económicos, ambientales y sociales. Se presentan en los reportes corporativos de las empresas comprometidas con el desarrollo sostenible, y son datos y mediciones de carácter voluntario. Surgieron inicialmente en Europa y luego se adoptaron en Estados Unidos. La expresión fue utilizada por primera vez por John Elkington en 1994, quien posteriormente expandió y articuló a fondo en su libro Cannibals With Forks.

Actualmente en Europa Occidental el 68\% de las multinacionales considera la elaboración de esta clase de reportes y en Estados Unidos, si bien el porcentaje es menor (41\%), el crecimiento es vertiginoso. En todos los casos, las empresas que presentan esta triple cuenta de resultados se han dado cuenta antes que otras que en el futuro inmediato el consumidor se volverá cada vez más responsable y exigirá saber cuál es el impacto económico, ambiental y social que generan los de indicadores de desempeño bajo los estándares del Global Reporting Initiative (GRI). Elaboración y control de presupuesto anual asignado al área. Analizar y gestionar las donaciones corporativas. Comunicar las acciones de responsabilidad social a todos los grupos de interés. El egresado tiene que conocer programas nuevos, a parte del conocimiento de programas de análisis como el ATLAS TI o el SPSS, Word, Excel, PPT.

Madison $\mathbf{M K}^{8}$, "empresa de investigación de mercados, con más de 20 años de experiencia en Europa y 5 en Perú, busca personal para ocupar el cargo de analista de proyectos, para realizar investigación de mercados, en diversos proyectos con público peruano, que desee formar parte de una empresa sólida de alto prestigio, y sobre todo que ofrece línea de carrera”. En este caso, el sociólogo debe estar preparado para realizar las coordinaciones internas que aseguren el desarrollo de cada proyecto a su cargo. Así como el seguimiento del trabajo de campo. Elaboración de cuestionarios, muestras, cronogramas y brindar valor agregado a los informes.

Requerimos Licenciado en Sociología y/o Trabajo Social". "Experiencia mínima de un año como especialista capacitador técnico y/o coordinador general de intervención social”. Este es un nuevo campo para los sociólogos, que antes no existía. Participar en la ejecución de obras como es "la construcción y/o mejoramiento y/o rehabilitación y/o instalación y/o mantenimiento y/o ampliación de sistemas de saneamiento de agua potable y/o alcantarillado, letrinas, reservorios, plantas de tratamiento de agua potable o aguas residuales. Saber hacer las coordinaciones entre todas personas que participan en estas obras, incluido la población beneficiaria".

Sociólogo ${ }^{10}$. "Servicio de supervisión y fiscalización de las actividades de comercialización del sub sector hidrocarburos en gas natural relacionados a facturación, pliego tarifario, corte y reconexión etc”. Profesional. Aquí solicitan un Sociólogo "Supervisor especialista en relaciones comunitarias vinculadas al sector energía y conocimiento en la supervisión de la implementación

productos que premia con su compra. Hasta el 2009, la elaboración y publicación de los mismos seguían siendo de carácter voluntario y evolutivo en todo el mundo.(Fuente: Wikipedia)

8 Empresa Madison MK, Lima, distrito de Miraflores, 18 de abril de 2017.

$9 \quad$ UNIOBRAS S.A.C - Lima, Lima, abril 2017.

10 Empresa OH PERU SAC, Lima, Santiago de Surco, 18 de abril de 2017. 
de la norma API 1162 Public Awareness Programs for Pipeline Operators"11.

Especialista en investigación y evaluación de proyectos. Formación: "Profesional titulado y colegiado en economía, o en sociología o en antropología, o en educación. Con Maestría en Gestión Pública o Gerencia Social Con estudios de post grado con no menos de 450 horas lectivas en Monitoreo y Evaluación de Proyectos de Inversión Pública y/o Programa Sociales o Gestión Social o Gerencia Política”. Aquí el profesional debe tener competencia en "evaluación de proyectos y programas de inversión pública. El recojo de información para estudios de línea de base o evaluaciones o en investigación o en estimación de indicadores cualitativos y cuantitativos en diversas realidades del país o como especialista en estudio" 12 .

Descripción de la empresa: "empresa dedicada al rubro de construcción, se encuentra en la búsqueda de un profesional (titulado y colegiado) en sociología, antropología o asistente social". Es un nuevo campo laboral para los sociólogos, por cuanto tiene que vercon la "ejecución y/o supervisión de obras como: rectificación y mejoramiento de la carretera, Construcción y ampliación de la carretera, rehabilitación y ampliación de la carretera, construcción y pavimentación de la carretera" 13

Empresa: Compartamos financiera, "busca egresado técnico o universitarios en antropología, sociología, trabajo social, psicología, educación, carreras administrativas o carreras afines". También es otro campo ocupacional para los sociólogos, que tiene que ver con el "trabajo en microfinanzas, donde puede ocupar el cargo de jefe de crédito grupal, coordinar, supervisar y formar a los Asesores de Negocios de Crédito Grupal para el cumplimiento de metas en cartera y clientes, apegándose a la metodología definida para la colocación del producto. Así como motivar, integrar y desarrollar al equipo de colaboradores para el cumplimiento de sus funciones propiciando su crecimiento personal y laboral. Supervisar el cumplimiento por cada trabajador de la unidad,

11 Las publicaciones de API necesariamente abordan problemas de naturaleza general. Con respecto a las leyes y regulaciones locales, estatales que deben ser revisadas.API no se compromete a cumplir con las obligaciones de los empleadores, fabricantes o proveedores de advertir y entrenar adecuadamente y equipar a sus empleados, y otros expuestos, con respecto a la salud y riesgos y precauciones de seguridad, ni asumir sus obligaciones bajo las leyes locales o estatales.

12 Pontificia Universidad Católica del Perú (PUCP) - Lima.

13 DYACONS S.A.C. - San Isidro, Lima proporcionándoles el soporte necesario para el logro de sus resultados. Exigen el dominio del Excel, Word, PPT"14.

Como se puede ver por los avisos que solicitan profesionales, los sociólogos pueden ejercer diversas actividades en el sector privado, compitiendo con otros profesionales de las ciencias sociales. Desde empresas que solicitan especialistas en relaciones comunitarias, conocimiento en responsabilidad social corporativa, elaboración y control del presupuesto anual, conocimiento en gestión de donaciones corporativas, investigación de mercados, trabajo de campo en seguimiento de proyectos, intervención social en la ejecución de obras de agua potable y/o alcantarillado, fiscalización de actividades de comercialización del sector hidrocarburos, evaluación de programas de inversión pública, supervisión de obras de rectificación, ampliación, mejoramiento de carreteras, supervisar y formar asesores de Negocios de Crédito, etc.

Definitivamente, hoy en día las empresas ven en los profesionales, que pueden realizar estas diversas actividades específicas, pero que a su vez exigen nuevos conocimientos como: el modelo del Triple Bottom Line, el Global Reporting Initiative (GRI), además de programas de análisis cuantitativo como el SPSS y programas de análisis cualitativo como el ATLAS TI entre otros muchos programas que existen.

En este sentido, la Escuela de Sociología, tiene que replantear su malla curricular en cuanto al manejo instrumental que hoy en día exige las empresas, sin descuidar su formación en cuanto a la investigación que permite crear nuevos conocimientos y un buen sustento teórico acorde al desarrollo de las teorías sociológicas en la actualidad.

El campo de trabajo de la Sociología es algo sumamente extenso, y tan flexible como lo es el propio sociólogo, de ahí surge el interés por determinar cuáles son las ocupaciones más comunes a las que se dedican los licenciados en sociología una vez que se encuentran con el mercado laboral. Una de las grandes inquietudes del estudiante, o futuro estudiante de sociología es "¿Qué me espera después de la carrera?". Las primeras pinceladas de estudio realizado con las encuestas a los mismos egresados, la demanda de las empresas a través de los avisos en periódicos o vía web, va mostrando la diversificación del campo ocupacional

14 Empresa Compartamos Financiera, Dpto. de Puno, Perú, 18 de abril de 2017. 
que va constituyéndose necesaria e indispensable tanto en el sector público como privado. Pero, requieren especialistas con un buen conocimiento de ciertos instrumentos de gestión, evaluación y programas de análisis.

En conclusión, las tendencias de la globalización de la economía y las comunicaciones a nivel mundial en las últimas décadas han condicionado de manera más notoria una segmentación del mercado de trabajo sobre la base del nivel de formación profesional. Hoy en día, la formación profesional a nivel de licenciatura resulta cada vez más insuficiente en un contexto laboral en el que los indicadores de calidad del empleo han disminuido para los menos cualificados requiriéndose del desarrollo de mayores competencias. En ese sentido, la investigación nos da cuenta que la experiencia laboral y los estudios de posgrado (maestrías, diplomados), han sido necesarios como mecanismos de inserción y permanencia en el empleo. En cuanto a la movilidad ocupacional, en términos del tránsito se observa que durante los primeros ańos los sociólogos no tienen estabilidad en una institución y se ven obligados a cambiar de empresa como de actividad, solo después de diversas experiencias laborales, logran una cierta estabilidad, con mejores condiciones salariales.

Repensar la sociología y la sociedad como un campo de reflexión y de estudio, supone plantear la existencia de ciertos saberes teóricos y metodologías, apoyadas en la validez epistemológica de la disciplina que todos los sociólogos compartimos, independientemente de cuál sea el campo específico de comprensión y explicación: política, cuestión urbana, cultural, organizacional, etc. Sin embargo, cada sub-campo posee objetivos y prácticas, modalidades de trabajo e intereses específicos que tensionan sobre los modos establecidos de hacer sociología. De este modo, la existencia de distintas esferas de práctica sociológica no da cuenta sólo de un ordenamiento en el espacio, sino también de la existencia de tensiones en las formas de comprender la sociología. No obstante, tanto en términos intelectuales como discursivos es el ámbito académico el que detenta la capacidad de legitimar los modos de hacer sociología; los desafíos planteados desde los otros espacios representan posicionamientos pragmáticos basado en la práctica, orientados a ampliar su reconocimiento (Lucas Rubinich: 2016).

\section{Educación y situación laboral de los padres de egresados de Sociología}

Estas breves anotaciones, acerca de la situación laboral y educativa de los padres de los egresados de sociología, ha sido por un lado para sustentar lo que hemos venido afirmando en las páginas anteriores, de que la identidad de las personas tiene mucho que ver con su procedencia familiar que implican diversos aspectos en lo social, económico, político e ideológico. Por otro lado, (sin el ánimo de desarrollar en profundidad) el proceso de movilidad intergeneracional implica condiciones objetivas de existencia entre padres e hijos. Los padres con una educación básica y una fuerte carga ideológica religiosa migran a las ciudades, adquieren una cierta identidad en sus representaciones y hábitos concretos en cuanto a sus comportamientos y relaciones con las demás personas. Definitivamente en el caso de los hijos además de la herencia cultural que reciben de los padres, está la cultura citadina con otras costumbres y hábitos; pero, principalmente se dan mejores condiciones ocupacionales, educativas y las expectativas para sus hijos son mucho mejores.

El interés por el estudio de la movilidad intergeneracional en el caso peruano es casi nulo, a diferencia de otros países como España, México, Argentina por ejemplo, donde cada vez más recobra fuerza en los últimos años. Por eso, uno de los objetivos de esta investigación también consistió en averiguar los antecedentes generacionales de los que estudian sociología en la Universidad Nacional Mayor de San Marcos. Explorar particularmente las diferencias existentes entre padres e hijos en términos de educación, ocupación y el lugar de origen.

Como se puede observar en el cuadro 4, los padres de la mayoría de estudiantes de sociología tienen origen provinciano del interior del país con empleos propios del lugar y con bajos ingresos económicos, en algunos casos son hijos de profesores, pero, principalmente personas dedicadas a la actividad agrícola y artesanal. Según los testimonios de algunos entrevistados que señalan que sus padres han nacido en Lima, y sus hijos pertenecen a la tercera generación cuyos abuelos han nacido fuera de Lima. Afirman que sus padres han tenido que trabajar mucho para lograr las condiciones básicas para la educación de sus hijos. Señalan que lograron ingresar a la universidad y se han convertido en profesionales, logrando mejores condiciones de vida en comparación al de sus padres y abuelos. 


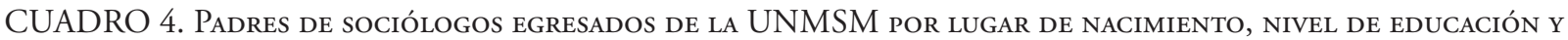
OCUPACIÓN. AÑo 2014

\begin{tabular}{|c|c|c|c|c|c|c|}
\hline \multirow{2}{*}{$\begin{array}{l}\text { No. } \\
\text { Enct }\end{array}$} & \multicolumn{3}{|c|}{ PADRE } & \multicolumn{3}{|c|}{ MADRE } \\
\hline & $\begin{array}{l}\text { Lugar de } \\
\text { Nacimien }\end{array}$ & Nivel educativo & Ocupación & $\begin{array}{l}\text { Lugar de } \\
\text { nacimient }\end{array}$ & Nivel educativo & Ocupación \\
\hline 1 & Lima & Superior uni & Contador & Lima & Super n.u* & cosmetóloga \\
\hline 2 & Cajamarca & Primaria & Obrero & Trujillo & Primaria & Ama de casa \\
\hline 3 & Lima & Primaria & Comerciante & Lima & Primaria & Ama de casa \\
\hline 4 & Lima & Superior uni & Contador & Lima & Superior n.u & Ama de casa \\
\hline 5 & Huancavelica & Primaria & PNP jubilado & Junín & Primaria & Ama de casa \\
\hline 6 & Cusco & Superior n.u* & $\begin{array}{l}\text { Técnico } \\
\text { Contabilida }\end{array}$ & Cusco & Superior n.u & Técnica enfermería \\
\hline 7 & Ayacucho & Secundaria & carpintero & Ayacucho & secundaria & Ama de casa \\
\hline 8 & Moquegua & Secundaria & PNP-jubilado & Arequipa & Primaria & Ama de casa \\
\hline 9 & Lima & Secundaria & Obrero & Ancash & Primaria & Ama de casa \\
\hline 10 & Lima & $\begin{array}{l}\text { Superior } \\
\text { universitario }\end{array}$ & Administrador & Lambayeque & Superior n.u & Secretaria \\
\hline 11 & Piura & Secundaria & Empleado público & Piura & Superior n.u & Ama de casa \\
\hline 12 & Puno & $\begin{array}{l}\text { Superior } \\
\text { universitario }\end{array}$ & Abogado & Lima & Primaria & Ama de casa \\
\hline 13 & Lima & Secundaria & agricultor & Lima & Secundaria & Agricultora \\
\hline 14 & Lima & Primaria & Zapatero & Lima & Secundaria & Ama de casa \\
\hline 15 & Piura & Superior n.u. & Joyero & Lima & Primaria & Ama de casa \\
\hline 16 & Junín & Superior n.u. & Comerciante & Cusco & Secundaria & Comerciante \\
\hline 17 & Ayacucho & Secundaria & Ambulante & Trujillo & Analfabeta & Ama de casa \\
\hline 18 & Lima & Secundaria & Comerciante & Huánuco & Secundaria & Comerciante \\
\hline 19 & Ancash & Primaria & Albañil & Ancash & Primaria & Ama de casa \\
\hline 20 & Ayacucho & Secundaria & Comerciante & Ayacucho & Secundaria & Comerciante \\
\hline 21 & Lima & $\begin{array}{l}\text { Superior } \\
\text { universitario }\end{array}$ & Técnico Deportivo & Puno & Superior n.u & Ama de casa \\
\hline 22 & Ancash & $\begin{array}{l}\text { Superior } \\
\text { universitario }\end{array}$ & $\begin{array}{l}\text { Sociólogo Docente } \\
\text { universitario }\end{array}$ & Lima & Superior & $\begin{array}{l}\text { Pedagoga y } \\
\text { socióloga }\end{array}$ \\
\hline 23 & Lima & Primaria & Mecánico & Ancash & Primaria & Ama de casa \\
\hline 24 & Ancash & Primaria & Carpintero & Ancash & primaria & Ama de casa \\
\hline 25 & Lima & Primaria & Agricultor & Lima & Primaria & Ama de casa \\
\hline
\end{tabular}

n.u. = no universitario

Fuente: Encuesta aplicada durante el mes de setiembre de 2014. Lima.

El cuadro 5 corrobora los datos recogidos con la aplicación de un cuestionario en el mes de marzo del ańo 2014, a los egresados que ya se encontraban trabajando ${ }^{15}$. La población estudiantil de la Universidad Nacional Mayor de San Marcos, provienen de los distritos con una fuerte presencia de migrantes provincianos como: Ate, Comas, San Martín de Porres,

15 X Curso de Reactualización para optar el título profesional en Sociología. Marzo, 2014, UNMSM.
Los Olivos, San Juan de Lurigancho, cuyos padres son migrantes que pertenecen a la primera o segunda generación. Son pocos los alumnos que residen en los distritos de clase media, como San Miguel, Jesús María, Breña, entre otros. Del total de 25 encuestados el mayor porcentaje reside en los distritos de Comas y San Martín de Porres. Son jóvenes hijos que en su mayoría son pequeños empresarios emprendedores, sin ninguna vinculación con el quehacer de las Ciencias Sociales. Precisamente, por eso, uno de los 
CUADrO 5: Egresados por lugar de residencia de la Facultad de Ciencias Sociales, año 20 i 4

\begin{tabular}{|c|c|c|c|c|c|}
\hline DISTRITO & No. & DISTRITO & No. & DISTRITO & No. \\
\hline Ancón & 1 & La Perla & 2 & San Isidro & 0 \\
\hline Ate & 17 & La Punta & 0 & San Juan de Lurigancho & 36 \\
\hline Barranco & 1 & La Victoria & 6 & San Juan de Miraflores & 18 \\
\hline Bellavista & 1 & Lima & 32 & San Luis & 1 \\
\hline Breña & 5 & Lince & 2 & San Martín de Porras & 30 \\
\hline Callao & 4 & Los Olivos & 14 & San Miguel & 5 \\
\hline Carabayllo & 6 & Lurín & 5 & Santa Anita & 1 \\
\hline Carmen de la Legua & 1 & Magdalena del Mar & 1 & Santa María del Mar & 1 \\
\hline Chaclacayo & 2 & Miraflores & 1 & Santa Rosa & 2 \\
\hline Chorrillos & 10 & Pachacamac & 2 & Santiago de Surco & 1 \\
\hline Cieneguilla & 2 & Pucusana & 1 & Surquillo & 0 \\
\hline Comas & 12 & Pueblo Libre & 0 & Villa El Salvador & 7 \\
\hline Agustino & 4 & Puente Piedra & 7 & Villa María del T. & 0 \\
\hline Independencia & 8 & Punta Hermosa & 0 & Otros & 36 \\
\hline Jesús María & 3 & Punta Negra & 1 & \multirow{4}{*}{\multicolumn{2}{|c|}{$\begin{array}{l}\text { Fuente: Base de datos de la Dirección Académica de } \\
\text { la Facultad de Ciencias Sociales, Enero, } 2015 .\end{array}$}} \\
\hline La Molina & 3 & Rímac & 4 & & \\
\hline La Perla & 2 & San Bartolo & 1 & & \\
\hline La Punta & 0 & San Borja & 2 & & \\
\hline
\end{tabular}

Fuente: encuesta a los alumnos del X Ciclo y egresados de la E.A.P. de Sociología (2014).

cuestionamientos obligados que hacen todos los padres de familia, cuando su hijo ha manifestado su vocación por la carrera de sociología, antropología, historia es un sentimiento de poco entusiasmo y posiblemente de malestar. Por cuanto aspiraban ver a sus hijos como: médicos, abogados, contadores o ingenieros. Por otro lado, todos los jóvenes que optaron por esta profesión se han visto en apuros al no poder dar respuesta acerca del quehacer ocupacional de esta carrera profesional. Asimismo, muchas instituciones aún desconocen de la existencia de esta profesión. Razón por el cual muchos jóvenes que egresan sólo con una formación general y sin especialización o cursos de posgrado, afrontan dificultades para insertarse en el mundo laboral y en ocasiones se ven relegados a la marginación laboral y como consecuencia se ven en la necesidad de buscar oportunidades de empleo en sectores totalmente ajenos a su formación profesional.

\section{A manera de recapitulación}

La trayectoria laboral e identidad profesional de los sociólogos, tiene su punto de partida con la institucionalización profesional de la sociología que se debió al desarrollo creciente del capitalismo, la industrialización, la migración del campo a la ciudad, así como al desarrollo de las ciencias y sus respectivas especializaciones, del cual surgen nuevas carreras profesionales como la antropología, la literatura, la historia, la arqueología, geografía; como también la fundación de numerosos institutos y centros de investigación en los países de América Latina, entre los años de 1930 y 1960.

La trayectoria laboral y desempeño profesional de los sociólogos en tiempos de cambio, es una trayectoria laboral desde el periodo de la Junta Militar de Gobierno que asumió el poder en 1968 e impulsó un conjunto de reformas radicales con el propósito de romper con el estado oligárquico, modernizar la economía y promover el desarrollo nacional. Es en este contexto que la primera etapa de la sociología se convierte en una disciplina privilegiada, por cuanto se abren varios ámbitos de intervención profesional. Espacios en el sector público como el Instituto Nacional de Planificación (INP), los Ministerios, Sistema Nacional de Apoyo a la Movilización Social (SINAMOS), Oficina Nacional de Cooperación Popular, Fondo de Cooperación al Desarrollo (FONCODES), CENCIRA, Organizaciones no Gubernamentales ONGs, Estas instituciones fueron los principales 
receptores de los egresados de la Universidad Nacional Mayor de San Marcos.

En la década del ochenta, con el levantamiento de los grupos terroristas como Sendero Luminoso y el MRTA. Los medios de comunicación, crearon en la población una imagen negativa acerca de los estudiantes de sociología, motivo por el cual los egresados tuvieron muchas limitaciones para incorporarse al mercado laboral. Hoy en día, con los cambios acelerados en la sociedad, el campo ocupacional se ha diversificado para muchas profesiones no solo de las ciencias sociales.

En estos últimos cincuenta años, los sociólogos han venido construyendo su identidad profesional, que hoy en día podemos afirmar que ya cuenta con cierto reconocimiento en la sociedad. Esto ha sido el resultado de la comprensión subjetiva de una compleja red de interrelación entre esferas, concepciones, espacio temporal y puntos de referencia individual y relacional. Como también está la formación universitaria y los planes de estudio y luego su inserción al mercado laboral y la dinámica particular de la institución.

Hoy en día, debido a que muchas empresas aún no tienen preciso acerca de las actividades específicas del profesional sociólogo, lo equiparan con otros profesionales como economistas, administradores, trabajadores sociales o antropólogos. Los servicios profesionales de los sociólogos tienen una alta demanda en el sector público; sin dejar de lado su creciente participación en el sector privado y en las organizaciones sociales. Desde el último tercio del siglo $\mathrm{XX}$, el sociólogo ha diversificado sus funciones.

En los últimos años los sociólogos han venido ocupando diversos espacios principalmente en el sector público: Ministros de Estado, congresistas, alcaldes, Dirección de la Biblioteca Nacional, gerencias $\mathrm{y}$ cargos directivos en gobiernos regionales y locales, medios de comunicación, investigadores con prestigio internacional, asesores, consultores nacionales e internacionales, entre otros. Las perspectivas del mercado de trabajo para esta profesión apuntan hacia un incremento en la demanda por parte de empresas privadas y organizaciones sociales. De igual forma se perciben mayores posibilidades en el ejercicio independiente, ya sea de manera individual, o a través de despachos de consultoría y servicios profesionales.

Finalmente, los estudiantes de sociología de la Universidad Nacional Mayor de San Marcos, son hijos (mayoritariamente) de familias que no tienen ninguna relación con las ciencias sociales, menos con la sociología. A pesar de ello, muchos jóvenes que concluyen su educación secundaria hoy en día ya conocen y se sienten motivados por estudiar esta carrera profesional como es la sociología.

\section{Bibliografía}

Bourdieu, Pierre (1990). Sociología y cultura, traducción de Martha Pou, Grijalbo, México.

Britos, Nora (2006). Ámbito profesional y mundo del trabajo. Politicas sociales y Trabajo Social en los noventa. Espacio Editorial, Bs.As.

Colás Bravo, Pilar (2007). "La construcción de la identidad de género: enfoques teóricos para fundamentar la investigación educativa”. Revista de de Investigación Educativa. Disponible: http:// www.redalyc.org/pdf/2833/283321895010.pdf.

Delgado Olivera, Carlos (2014). Confesión de parte de Fredy Gambeta. (4 parte).

Domínguez Romero, Luis (2016). Nacionalismo y militarismo en el Perú: 1968-1980. Facultad de Ingeniería, UNAM.

Erickson, M.S. (1968). Identidad, juventud y crisis; Madrid, Taurus. http:/www.posgrado.unam.mx/ sites/default/files/2016/04/1614.pdf http://cultura2.sociales.uba.ar/files/2013/05/_.pdf http://www.peruanita.org/personaggi/gambetta/ confesion3.htm.8-11-2014.

López, Sinesio (1990). "Intelectuales y políticos en el Perú del Siglo XX», en: Pensamiento político peruano 1930-1968. DESCO, Lima, p. 40

Lucas Rubinich, Gastón J. Beltrán (2013): / editores ¿Qué hacen los Sociólogos?

LyNCH, N. (2016). «Despojo a la universidad pública». La República. Lima.

Medina, N. (2013). «Influencia de los padres en la elección de carrera». Ponencia en décimo séptima exposición de orientación vocacional. México: UNAM.

Pena, M.A.; Buschiazzo, L. (2006). Elección de carreras universitarias y género. El caso de trabajo social e ingeniería. Tesis. Santiago. Universidad de Chile.

Polanyi, Karl (1997). La gran transformación. Critica del liberalismo económico. Madrid: Ediciones La Piqueta, presentación y traducción de Julia Varela y Fernando Álvarez-Uria. 
Quiroz, M. T. (2004). El impacto de las tecnologías del conocimiento y la comunicación en el pensar sentir de los jóvenes. Tesis de Doctor en Ciencias Sociales. Lima: UNMSM.

Wikipedia.

Ruvalcaba-Gayoso, J. Uribe A, I. Gutiérrez G.,R. (2011). Identidad e identidad profesional: Acercamiento conceptual e investigación contemporánea. Revista CES Psicología, 4(2), 82-102.
Vargas Morales, Z.E. (2006). "El lugar de la sociología en las ONG y en la enseñanza universitaria. Un dilema no resuelto. Reflexiones y propuestas». En Estudios Sociales, revista del Instituto de Investigaciones Histórico Sociales, No 16, agosto 2006 